\title{
Korleis går det med intensivpasientane?
}

\author{
Samandrag \\ Bakgrunn. Intensivmedisinen tek hand \\ om kritisk sjuke pasientar. Dei seinare \\ to tiåra har det vore meir interesse \\ for å fylgje opp intensivpasientane og \\ undersøkje korleis det går vidare med \\ overlevarane.
}

Materiale og metode. Artikkelen er bygd på eit ikkje-systematisk litteratursøk i PubMed, og referanseartiklar er valde ut etter forfattarane sitt skjønn. Artikkelen er i tillegg basert på data frå forfattarane si eiga systematiske oppfylgjing av intensivpasientar.

Resultat. I Noreg overlever over $80 \%$ av intensivpasientane sjukehusopphaldet. Frå kring to år etter intensivopphaldet har tidlegare intensivpasientar same vidare leveutsikter som normalpopulasjonen. Intensivpasientar som gruppe har før innlegging til intensivbehandling meir komorbiditet og redusert livskvalitet og funksjonsevne samanlikna med befolkninga elles. Livskvaliteten aukar med tida etter intensivopphaldet, og dei fleste vert sjølvhjulpne.

Fortolking. Sjølv hos pasientar med grunnlidingar og kritisk sjukdom er det i mange tilfelle rehabiliteringspotensial. Dei fleste langtidsoverlevarane oppnår akseptabel livskvalitet. Intensivpasientar utgjer ei heterogen gruppe, der forløp og langtidsresultat varierer mykje. Intensivmedisinsk praksis bør difor organiserast slik at ein kan fylgje opp pasientane også etter utskriving frå sjukehuset.

\section{Reidar Kvåle}

reidar.kvale@helse-bergen.no

Hans Flaatten

Kirurgisk serviceklinikk

Haukeland universitetssjukehus 5021 Bergen

Intensivmedisin er spesialisert overvaking, intervensjon og behandling av kritisk sjuke pasientar. Hovudmåla er å oppretthalde livsviktige organfunksjonar og førebyggje organsvikt. Ei lang rekkje lidingar, tilstandar og skadar kan føre til kritisk sjukdom, og intensivpasientar er difor ei svært heterogen gruppe, der fellesnemnaren er trugande eller manifest organsvikt. Gjennomsnittspasienten er såleis vanskeleg å finne.

Det er fleire grunnar til at ein dei seinare åra har sett nøyare på korleis det går med intensivpasientane. Intensivmedisinen er komplisert, høgteknologisk og ressurskrevjande både når det gjeld personell, utstyr og medisinar. Det er naturleg at ein granskar kva som vert resultatet av denne innsatsen, både med tanke på samfunnsøkonomi og utvikling av faget. Vidare gjer moderne teknologi og behandlingsalternativ det no mogeleg å forlenge livet til pasientar som tidlegare ikkje ville overlevd. Intensivmedisinen er prega av stadig fleire intervensjonar og meir avansert behandling på ein stadig sjukare og eldre pasientpopulasjon. Dette inneber etiske val og utfordringar knytte til kapasitet og prioritering. Ein må kartleggje korleis det faktisk går med pasientane for å vite meir om i kva grad ein verkeleg gjev intensivbehandling til dei rette pasientane. Ingen er tente med at pasientar vert utsette for behandling dei ikkje har noka nytte av.

For overlevarane er sjølvsagt det viktigaste kva funksjonsevne og livskvalitet dei oppnår etter intensivbehandlinga. Dette er pasientane sitt perspektiv, og hovudtema for denne artikkelen.

\section{Materiale og metode}

Denne artikkelen er basert på ikkje-systematiske litteratursøk i PubMed. Artikkelforfattarane har frå år 2001 publisert nokre artiklar på dette feltet, og det er brukt data frå eiga forsking, så vel som tal frå Norsk Intensivregister. Referanseartiklane er valde ut etter eige skjønn.

\section{Resultat etter intensivbehandling}

Intensivpasientane representerer ikkje noko gjennomsnitt av befolkninga. Det er godt dokumentert at dei som gruppe i utgangspunktet har meir komorbiditet og meir redusert fysisk kapasitet enn normalpopulasjonen (1-3). Det er mange måtar å organisere og drive intensivmedisin på, og det finst såleis både lokale, regionale, nasjonale og internasjonale skilnader (4). Ulike intensivpopulasjonar er difor vanskelege å samanlikne direkte. Ein lyt då særleg ta omsyn til pasientutvalet (case mix), der dei viktigaste faktorane er alder, alvorsgrad av aktuell sjukdom, komorbiditet, hastegrad og diagnose.

For pasientane sin del kan resultata etter intensivbehandlinga avgrensast til to hovudpunkt:

- I kva grad overlever pasientane?

- Kva for liv får overlevarane etterpå?

Det må understrekast at under intensivopphaldet er det som oftast mange spesialitetar og faggrupper på sjukehuset som er involverte $\mathrm{i}$ behandlinga. Resultatet etter intensivbehandling kan difor sjølvsagt ikkje tilskrivast intensivbehandlinga åleine. $\mathrm{Og} \mathrm{i}$ tida etter intensiv- og sjukehusopphaldet er det andre grupper som også er avgjerande for langtidsresultatet og kva liv overlevarane får.

I alle intensivpopulasjonar vil dei fleste dødsfalla skje i den tidlege, akutte fasen. Skjematiske overlevingskurver for ein intensivpopulasjon og for ei kjønns- og aldersjustert kontrollgruppe i normalpopulasjonen kan sjå ut som dei i figur 1 .

Det tidlege, bratte fallet i overleving representerer intensivmortalitet (a) og sjukehusmortalitet (b), som i hovudsak er knytte til aktuell sjukdom/skade og komplikasjonar. Etter utskriving frå sjukehus er nye dødsfall meir knytte til forverring av kronisk

\section{Hovudbodskap}

- Intensivpasientar er ei heterogen gruppe, som har meir komorbiditet enn befolkninga elles

- Over $80 \%$ av norske intensivpasientar overlever sjukehusopphaldet

- Dei fleste overlevarane vert sjølvhjulpne og får ein akseptabel livskvalitet

- Overlevarane har eit svært variabelt sjukdomsforløp, og bør fylgjast opp etter sjukehusopphaldet 
sjukdom (hjarte- og karsjukdom, lungesjukdom, diabetes og anna), cancer og endestadium av organsvikt (c). Etter ei tid vert vidare overleving tilnærma parallell med overlevinga til ei kjønns- og aldersjustert gruppe i populasjonen $(d)(5,6)$.

Når ein skal granske overleving for intensivpasientar, burde ein ideelt sett samanlikne med kjønns- og aldersjusterte grupper av sjukehuspasientar med same tilstand/sjukdom, men utan trong for intensivbehandling. Slike kontrollgrupper er svært vanskelege å finne, og det vanlege er å samanlikne med justerte grupper frå normalpopulasjonen, utarbeidde av Statistisk sentralbyrå (7).

Når ein skal samanlikne langtidsoverleving for intensivpasientar med kontrollgrupper, er det viktig å gjere fleire samanlikningar frå ulike tidspunkt etter innlegging på intensiveininga. Dersom ein berre tek utgangspunkt i fase (a) og (b), og inkluderer den initialt høge mortaliteten, vil nær sagt alle intensivpopulasjonar ha auka mortalitet i høve til normalpopulasjonen, same kor lang tid ein fylgjer opp etterpå.

\section{Intensivmortalitet og sjukehusmortalitet}

I det fylgjande er omgrepet mortalitet brukt om dødelegheit. Intensivmortalitet tyder altså den delen av pasientgruppa som døyr på intensivavdelinga, medan sjukehusmortalitet tyder den delen som døyr i løpet av sjukehusopphaldet. Internasjonale studiar har funne at gjennomsnittleg intensivmortalitet ligg i området $10-22 \%$, og at total sjukehusmortalitet er kring $20-30 \%$. Intensivmortaliteten representerer såleis vanlegvis to tredelar av sjukehusmortaliteten. Det er gjort store multisenterstudiar av kva faktorar som påverkar mortalitet for intensivpasientar, og utarbeidd system som skårar prognose ut frå alvorsgrad. Ulike versjonar av Acute Physiology And Chronic Health Evaluation (APACHE) og Simplified Acute Physiological Score (SAPS) er i utstrekt bruk internasjonalt (8, 9). Ved hjelp av slike skåringssystem kan ein estimere sjukehusmortalitet for grupper av pasientar, og måle standardisert mortalitetsratio, som er observert/forventa mortalitet. Ein verdi under 1 tyder altså betre overleving enn ein skulle forvente ut frå kor alvorleg sjuke pasientane var.

Dei faktorane som i størst grad påverkar sjukehusmortaliteten til intensivpasientar er alvorsgrad av tilstanden under intensivopphaldet, alder, om innlegginga er akutt eller planlagt, og diagnostisk kategori (pasientar med indremedisinske problem har gjennomsnittleg høgare mortalitet enn kirurgiske pasientar) (5). Komorbiditet har faktisk lite å seie for sjukehusmortaliteten, men når det gjeld langtidsoverleving er komorbiditet viktig $(5,10)$.

\section{Langtidsoverleving}

Det er sjølvsagt svært varierande langtidsoverleving for ulike kategoriar intensivpasientar når ein ser på hovuddiagnosar. I ein finsk studie fann ein til dømes relativ (observert/forventa) overleving frå innlegging på intensiveining og fem år fram i tid å vere $82 \%$ for pasientar med intoksikasjonar, $78 \%$ for dei med traume, $47 \%$ for dei med respirasjonssvikt og $25 \%$ for pasientar som hadde hatt hjartestans (5). Sidan grupper av intensivpasientar har auka mortalitet også frå to år etter intensivopphaldet, tyder det at andre grupper av intensivpasientane må ha høgare overleving enn normalpopulasjonen, sidan gjennomsnittleg overleving er lik. Kanskje er det slik at nokre av dei som overlever kritisk sjukdom og skade, er betre rusta genetisk og immunologisk enn gjennomsnittet i befolkninga.

Nyare studiar har funne auka gjennomsnittleg mortalitet hos intensivpasientar samanlikna med normalpopulasjonen også lenger enn to år, heilt opp til 15 år etter intensivopphaldet $(11,12)$ Den auka mortaliteten heng fyrst og fremst saman med tre faktorar: alder, alvorsgrad av tilstanden og diagnostisk kategori og komorbiditet.

\section{Norske data}

Norsk Intensivregister (NIR) har 32 intensiveiningar som medlemmer, og femner såleis truleg om over $95 \%$ av norsk intensivbehandling. Registeret inneheld opplysningar om tal på intensivopphald, alder, kjønn, liggjetid, respirasjonsstøtte, alvorsskår (SAPS), ressursbruk (Nine Equivalents of nursing Manpower use Score - NEMS), innleggingskategori og vitalstatus. Årleg registrerer Norsk Intensivregister kring 11000 opphald for 10000 intensivpasientar.

Data for 2006 syner at $80,7 \%$ av intensivpasientane overlever sjukehusopphaldet (84,2\% på regionsjukehusnivå, $82,5 \%$ på lokalsjukehusnivå og $78,2 \%$ på sentralsjukehusnivå) (13). Intensivmortaliteten er 11,0-16,7\%, medan sjukehusmortaliteten etter intensivopphaldet er 4,2-6,5\%.

I heile materialet er standardisert mortalitetsratio (SMR) under 1 (det døyr altså færre pasientar enn ein skulle forventa ut frå alvorsskår under intensivopphaldet), og det er godt samsvar mellom alvorsskår og mortalitet. Diverre har ikkje registeret tilgang på personidentifiserbare data, så vi har ikkje høve til å undersøkje vidare overleving etter sjukehusopphaldet på landsbasis. Det er som nemnt gjort studiar av langtidsmortalitet ved einskildsenter $(1,6)$.

\section{Funksjonsnivå og livskvalitet etter intensivopphald}

Det har dei siste 20 åra vore utvikla mange ulike måleinstrument for funksjonsevne, og ikkje minst for helserelatert livskvalitet: sjukdomsspesifikke og generelle, ein- og fleirdimensjonale, validerte og ikkje-validerte, nasjonale og internasjonale. Dette kan gjere det nærast umogeleg å samanlikne studiar, men det er etter kvart kome tilrådingar når det gjeld kva måleinstrument ein bør bruke (14). Når det gjeld funksjonsevne, er

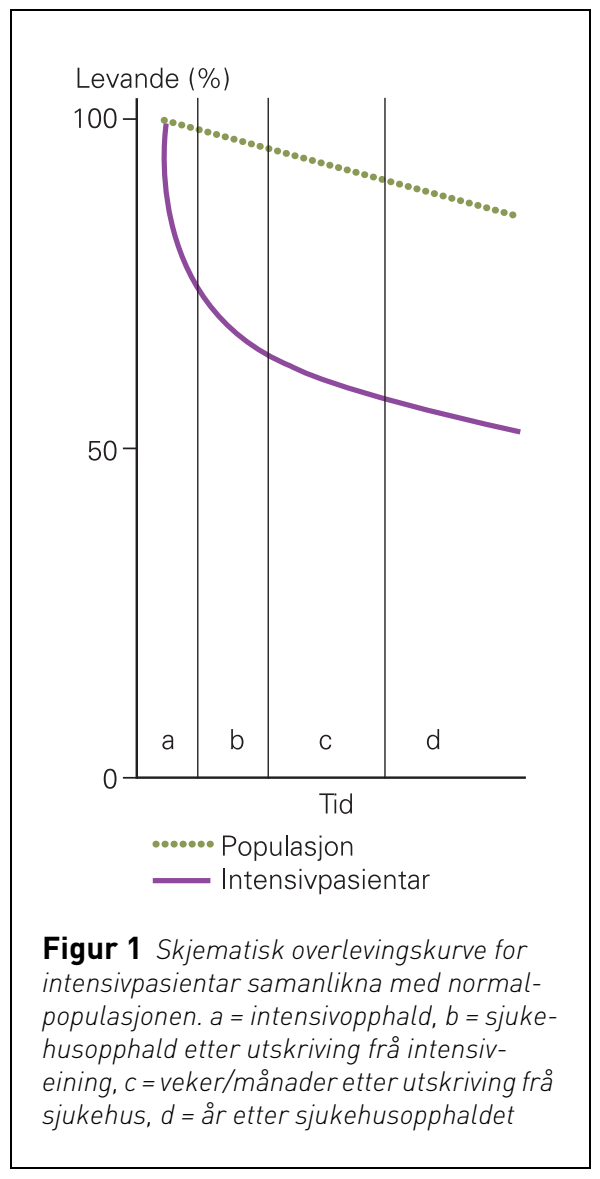

Karnofsky Index og Katz'Activities of Daily Living (ADL) blant dei tilrådde måleinstrumenta $(15,16)$.

I ein oversiktsartikkel vart 21 studiar med til saman 7320 pasientar granska. Pasientane var representative for vaksne overlevarar etter intensivopphald, og var undersøkte med validerte og generelle måleinstrument tilrådde for måling av livskvalitet (Medical Outcomes Study 36-item Short Form (SF36), EuroQol-5D, Sickness Impact Profile og Nottingham Health Profile) (17).

Hovudfunna var at samanlikna med normalpopulasjonen hadde overlevarar etter intensivopphald lågare skår for livskvalitet før intensivopphaldet. Dette heng saman med at intensivpasientar (særleg dei med medisinske problem) har større grad av komorbiditet på førehand. Etter utskriving frå sjukehus steig skåren til intensivpasientane, men var framleis lågare enn skåren i normalpopulasjonen. Her har andre studiar vist at etter seks månader har traumepasientar og dei med respirasjonssvikt mest redusert skår, medan eldre var nærare populasjonsskåren. Fysisk funksjonsevne er mest påverka av alder og alvorsgrad av sjukdom, og det går generelt raskare med psykisk rehabilitering enn med fysisk (18).

Ein norsk studie frå ei blanda, generell intensiveining (70\% kirurgiske pasientar, $30 \%$ medisinske) synte at seks månader etter intensivopphaldet skåra overlevarar signifikant lågare enn normalpopulasjonen $\mathrm{i}$ alle åtte områda i SF-36 (fysisk funksjon, 

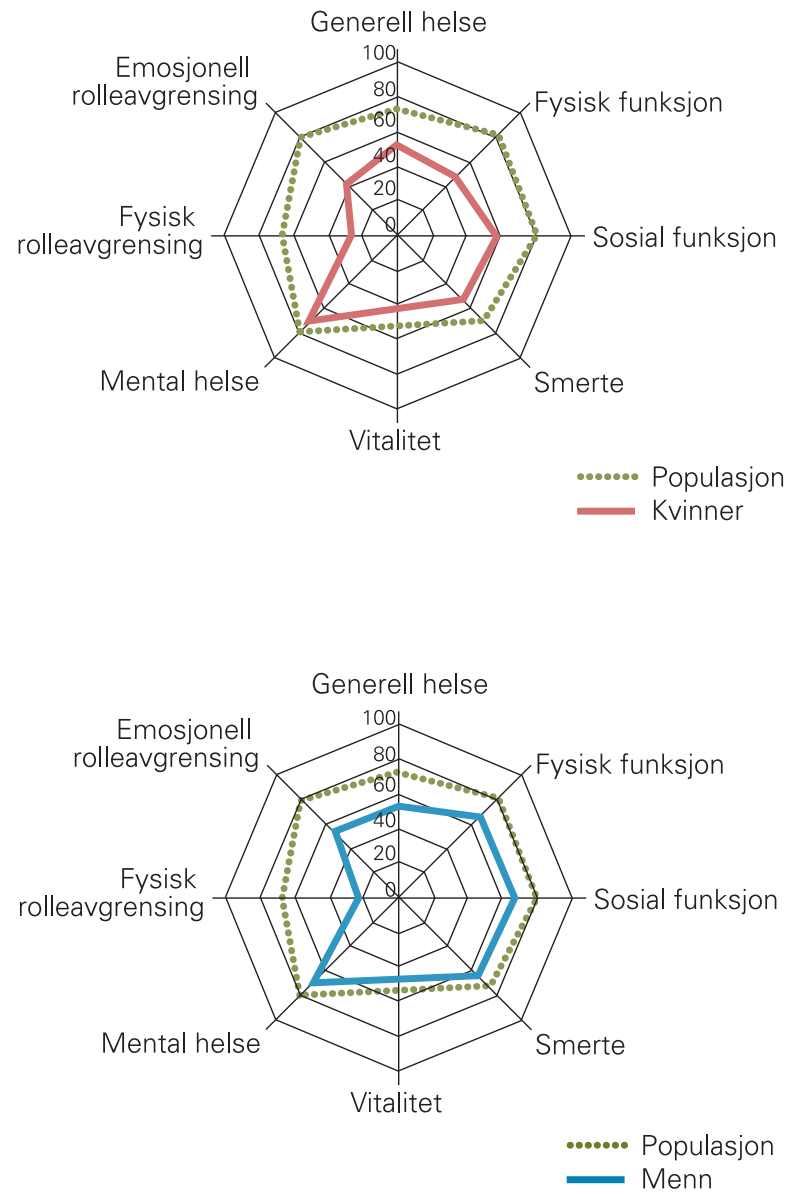

Figur 2 Helserelatert livskvalitet (Short Form 36) seks månader etter intensivopphaldet hos menn ( $n=87)$ og kvinner ( $n=55)$ samanlikna med norske, aldersjusterte populasjonsdata. Basert på resultat frå (19)

sosial funksjon, smerte, vitalitet, mental helse, fysisk rolleavgrensing, emosjonell rolleavgrensing og generell helse) (19). Det var minst reduksjon i mental helse (fig 2).

Fysisk funksjonsevne vart i denne studien målt med Karnofsky Index. Av 136 pasientar som vart fylgde opp med ettersamtalar, var det $39 \%$ som hadde mindre eller ingen symptom og avgrensingar på aktivitet, og $75 \%$ greidde seg i kvardagen utan hjelp frå andre.
Oppgitte interessekonflikter: Ingen

1. Loes O, Smith-Erichsen N, Lind B. Intensive care cost and benefit. Acta Anaesthesiol Scand Suppl 1987; 84: 3-19.

2. Lipsett PA, Swoboda SM, Dickerson J et al. Survival and functional outcome after prolonged intensive care unit stay. Ann Surg 2000; 231: 262-8.

3. Wehler M, Martus P, Geise A et al. Changes in quality of life after medical intensive care. Intensive Care Med 2001; 27: 154-9.

\section{Litteratur}

4. Ridley S, Burchett K, Gunning K et al. Heterogeneity in intensive care units: fact or fiction? Anaesthesia 1997; 52: 531-7.

5. Niskanen M, Kari A, Halonen P. Five-year survival after intensive care - comparison of 12,180 patients with the general population. Crit Care Med 1996; 24: 1962-7.

6. Flaatten H, Kvale R. Survival and quality of life 12 years after ICU. A comparison with the general Norwegian population. Intensive Care Med 2001; 27: $1005-11$.

7. Statistisk sentralbyrå. www.ssb.no. (15.10.2008).

8. Knaus WA, Zimmermann JE, Wagner DP et al. APACHE - acute physiology and chronic health evaluation: a physiologically, based classification system. Crit Care Med 1981; 9: 591-7.

9. LeGall JR, Lemeshow S, Saulnier F. A new simplified acute physiology score (SAPS II) based on a European/North American multisenter study. JAMA 1993; 270: 2957-63.

10. Dragsted L, Qvist J, Madsen M. Outcome from intensive care. IV. A 5-year study of 1308 patients: long-term outcome. Eur J Anaeshesiol 1990; 7: $51-62$.

11. Williams TA, Dobb GJ, Finn JC et al. Determinants of long-term survival after intensive care. Crit Care Med 2008; 36: 1523-30.

12. Wright JC, Plenderleith L, Ridley SA. Long-term survival following intensive care: subgroup analysis and comparison with the general population. Anaesthesia 2003; 58: 637-42.

13. Norsk Intensivregister. Årsrapport 2006. www.intensivregister.no/LinkClick.aspx?fileticket $=10 \mathrm{~d} 1 \mathrm{As} \times 1 \mathrm{~s} 3 \mathrm{~g} \% 3 \mathrm{D} \& \mathrm{tabid}=55 \& \mathrm{mid}=377$ (20.11.2009).

14. Hayes JA, Black NA, Jenkinson C et al. Outcome measures for adult critical care: a systematic review. Health Technol Assess 2000; 4, nr. 24 $1-111$.

15. Schag CC, Heinrich RL, Ganz PA. Karnofsky performance status revisited: reliability, validity, and guidelines. J Clin Oncol 1984: 2: 187-93.

16. Katz S, Ford AB, Moskowitz RW et al. Studies of illness in the aged. The index of ADL: a standardized measure of biological and psychological function. JAMA 1963; 185: 914-9.

17. Dowdy DW, Eid MP, Sedrakyan A et al. Quality of life in adult survivors of critical illness: a systematic review of the literature. Intensive Care Med 2005; 31: 611-20

18. Niskanen M, Ruokonen E, Takala J et al. Quality of life after prolonged intensive care. Crit Care Med 1999; 27: 1132-9.

19. Kvåle R, Ulvik A, Flaatten H. Follow-up after intensive care: a single center study. Intensive Care Med 2003; 29: 2149-56.

Manuskriptet ble mottatt 24.10. 2008 og godkjent 20.5. 2009. Medisinsk redaktør Are Brean. 